\title{
What are the Particularities of Oesophageal Surgery in Cirrhotic Patients
}

\author{
Christian Hobeika', Mathieu Messager ${ }^{2,3}$, Guillaume Piessen $^{2}$ \\ 1Departement of Hepatobiliary Surgery and Liver Transplantation, Beaujon Hospital, AP-HP, Clichy, France \\ ${ }^{2}$ Univ. Lille, Department of Digestive and Oncological Surgery, Claude Huriez University Hospital, F-59000 Lille, France \\ ${ }^{3}$ Departement of Digestive Surgery, Gustave Dron Hospital, Tourcoing, France
}

Corresponding author:

Professor Guillaume Piessen

Department of Digestive and

Oncological Surgery

Claude Huriez University Hospital

2 Avenue Oscar Lambret, 59000 Lille

France

E-mail: guillaume.piessen@chru-lille.fr

\section{Rezumat}

Care sunt particularitățile chirurgiei esofagiene la pacienții cirotici

Scopul acestei lucrări a fost de a trece în revistă întreaga literatură despre chirurgia esofagiană pentru a defini în mod adecvat indicațiile chirurgicale şi specificul managementului lor terapeutic. Cercetarea bibliografică a fost realizată pe Pubmed în perioada ianuarie 1995 - iunie 2015, folosind franceza şi engleza ca limbi de publicare.

Cuvinte cheie: ciroza hepatică, esofagectomie, cancer esofagian

\section{Abstract}

The aim of this paper was to review the entire literature on esophageal surgery to best define the surgical indications and the specifics of their management. The bibliographic research was carried out on Pubmed between January 1995 and June 2015, using French and English as publication languages.

Key words: liver cirrhosis, esophagectomy, esophageal cancer

\section{Introduction}

Esophagectomy in the cirrhotic patient is a rare situation. In the esophagectomy series for cancer, $3 \%$ to $7 \%$ of patients are cirrhotic $(1,2)$. This is most often a situation of exclusion from 
randomized trials and other types of clinical studies. Thus, few data in the literature specify the surgical indication criteria and balance surgical morbidity with cirrhotic patient's survival benefit. This work's objective was to review all of the literature on the subject in order to best define the surgical indications and management specifics.

\section{Research Carried Out}

The bibliographic research was done on Pubmed $^{\circledR}$ over the period from January 1995 to June 2015, using French and English as publication languages. The keywords retained were "liver cirrhosis" (Mesh) and "esophagectomy" (Majr). This search identified 4 articles of which only the summaries were available and one that was in Japanese. Searching for the terms "liver cirrhosis" (Mesh) and "esophagectomy" (Majr) did not find any more items. The search was extended with the Google Scholar ${ }^{\circledR}$ tool, the references of the articles consulted, to retain a total of 17 articles (Table 1).

\section{Surgical Indications}

The two main indications treated are oesophageal cancer and esogastric devascularization surgery.
The esophagectomy indications in the selected papers are for malignant pathologies, mainly for squamous cell carcinomas, related to alcohol intoxication, which is the predominant cause of cirrhosis in the populations studied (3).

Patients with cirrhosis are 2.6 times more likely to develop oesophageal cancer in their lifetime. This risk is all the greater if they consume alcohol and tobacco. The cirrhotic patient's oesophageal cancer incidence is around $3 \%(4)$.

The last report of 2010 on the cirrhotic surgery of the FMC-HGE (French Association of Continuous Medical Training in HepatoGastro-Enterology) and the national thesaurus of digestive cancerology of 2016 classifies decompensated cirrhosis and/or the simple presence of oesophageal varices (even if CHILD A without a history of decompensation) as an absolute contraindication to oesophageal surgery, however compensated cirrhosis without varicose veins is a relative contraindication (5).

\section{The Esogastric Devascularisation}

Esogastric devascularisation or modified Sugiura intervention (more or less associated with a splenectomy) is a heavy surgical technique aimed at treating oesophageal

Table 1. Summary of the level of evidence of the studies included in the literature review

\begin{tabular}{lc}
\hline Level of Scientific Evidence Provided by the Literature & Number of articles \\
\hline Level 1 & 0 \\
High-power randomized controlled trials & \\
Meta-analysis of randomized controlled trials \\
Decision analysis based on well-conducted data & 0 \\
\hline Level 2 & \\
Low-power randomized controlled trials \\
$\quad \begin{array}{l}\text { Well-conducted non-randomized comparative studies } \\
\text { Cohort studies }\end{array}$ \\
\hline $\begin{array}{l}\text { Level } 3 \\
\text { Case-control study }\end{array}$ \\
\hline Level 4 \\
$\quad$ Comparative studies with significant biases & 17 \\
$\quad$ Retrospective studies \\
Case series
\end{tabular}


varices causing digestive haemorrhage. It is rarely prescribed, usually when the bleeding is resistant to endoscopic treatment, and the placement of a TIPS is contraindicated or technically impossible, and if there is a contraindication to liver transplantation or a haemorrhagic emergency context (6). A recent series by Voros et al (7) including 46 patients found a rate of oesophageal fistulas of $10.8 \%$, $15.5 \%$ of decompensation of liver function, $26 \%$ of ascites, including $4.3 \%$ refractory, $6.5 \%$ of hepatorenal syndrome. Regarding the 30 -day post-operative mortality, it is $23.9 \%$ in total, but it is halved for CHILD B patients and it is zero for CHILD A patients. On an average follow-up of 10 years, $41 \%$ will not suffer from a haemorrhagic recurrence. Other series tend to show the feasibility of this technique (8).

Compensated cirrhosis is a relative contraindication for a cancer-related esophagectomy. The indication can only be given by an expert centre, in extremely well selected patients (Expert advice).

Esogastric devascularization interventions are indicated as a last resort in the treatment of oesophageal varices causing digestive haemorrhages (Expert advice).

\section{Oesophageal Cancer}

\section{Technical specifications}

There have been no reports in the literature assessing technical features such as haemostasis procedures in cirrhotic patients with oesophageal cancer.

\section{Preoperatively and intraoperatively}

In the series by Fékete et al., the approach did not influence the postoperative mortality from esophagectomy in cirrhotic patients (Fekete) (NP4). There is no argument in the literature to modify the first approach (transthoracic versus transhiatal resection), the anastomosis type (cervical anastomosis versus intrathoracic) or the resection extent, in a cirrhotic patient (9).

Regarding lymph node dissection, performing extensive dissection seems associated with a higher risk of postoperative ascites (10). Some autopsy series have shown that in patients with portal hypertension the diameter of the lymphatic vessels was higher as compared with the control group, especially for the peri-gastric and perioesophageal lymphatic networks (11). There is however no argument in the literature to modify the lymph node dissection extent in a cirrhotic patient. Performing meticulous surgery in the lymph node areas, with lymphostasis and careful haemostasis is desirable.

It has been described in the form of a case report, the production of a venous shunt during an esophagectomy in the event of associated portal hypertension, with the occurrence of hepatic encephalopathy in one of the 2 patients (12).

After esophagectomy in cirrhotic patients, short post-operative drainage (3-5 days) is recommended (10).

There is no argument in the literature to modify the approach route, the anastomosis type, the resection extent, the dissection extent (Expert Agreement). The achievement of meticulous lymphostasis associated with a short postoperative drainage (3-5 days) is recommended (Expert agreement).

\section{Postoperatively}

Faced with the increased risk of postoperative morbidity and mortality (see chapter below), a team proposed that patients with parenteral nutrition should be fasted for 2 weeks (13). This is a centerdependent attitude and there is no argument in the literature to modify post-operative management after esophagectomy on a cirrhotic patient.

There is no argument in the literature to modify the post-operative follow-up after esophagectomy in a cirrhotic patient (Expert agreement). 


\section{Results of surgery for cancer}

Short-term results: postoperative morbidity and mortality

Oesophageal cancer surgery, even in non-cirrhotic patients, is associated with significant morbidity and mortality. In Europe, 30-day mortality varies between 1.9 and $5.8 \%$ depending on the country, with a 2 -year survival which varies from 56.8 to $61 \%$ (14). A recent meta-analysis shows that longterm survival is significantly improved when this surgery is performed in specialized centres (15). The morbidity of esophagectomies varies between 40 and 50\% (16).

Cirrhotic patients' oesophageal surgery morbidity and mortality literature data are limited. However, the retrospective series of Fekete et al (17), Lu et al (13) and Tachibana et al (2) show that the morbidity rate is much higher in cirrhotic patients and varies between 83 and $87 \%$, and between 17 and $30 \%$ for the mortality rate. These 3 series bring together a total of 57 patients with proven histological cirrhosis who had surgical treatment for oesophageal cancer between 1979 and 2003.

Concerning postoperative morbidity, the rates of infectious pulmonary complications and anastomotic fistulas vary from 17 (17) to $27 \%$ (2) and 11 (2) to 13\% (17) respectively. These rates are comparable to those found in the literature over comparable periods, namely $9.8 \%$ fistulas and $24.4 \%$ pulmonary complications (10).

Regarding cirrhosis-specific morbidity, the series by Fekete et al. reports $65 \%$ ascites, $39 \%$ liver failure, $13 \%$ hepatorenal syndrome, $4.3 \%$ portal thrombosis. Cirrhosis does not appear to affect the anastomotic fistulas and respiratory complications rate. But cirrhotic patients' acute complications in postoperative context worsen morbidity and postoperative mortality.

Regarding mortality, two thirds of deaths are linked to a cirrhosis complication. Hepatorenal syndrome is statistically linked to $100 \%$ mortality and ascites to $33 \%$. In the series by Fekete et al, the causes of post- operative death were: anastomotic fistula in 2 patients, hepatorenal syndrome in 3 patients, and one case of mesenteric thrombosis with mesenteric ischemia (17).

The series of $\mathrm{Lu}$ et al (13) highlights, within its population, a mortality rate of $10 \%$ (approaching a mortality rate of the standard population) for CHILD A versus 50\% and $100 \%$ for stages B and C. In addition, they show that there is a statistically significant difference between living patients and those who died post-operatively, concerning the serum albumin level, PT, the presence of ascites.

As a result, 3 items of the CHILD score (PT, albuminemia and ascites) are the predictors of post-operative mortality:

- a Child score> A;

- a prothrombin level $<60 \%$;

- severe weight loss ( $>10 \%$ of body weight) associated with hypoalbuminemia $<34$ $\mathrm{g} / \mathrm{l}(2)$. Note that weight loss $>15 \%$ not recovered after nutrition is a relative contraindication and a criterion for inoperability even in the non-cirrhotic patient.

Esophagectomy for oesophageal cancer in cirrhotic patients is feasible in patients with CHILD A cirrhosis, with no history of decompensation and without oesophageal varices, in an expert centre (GRADE C).

Hepatocellular insufficiency is the major predictor of morbidity and mortality (GRADE C).

Postoperative decompensation of portal hypertension is associated with a poor prognosis (GRADE C).

Cirrhosis is not a risk factor for anastomotic fistula (GRADE C).

\section{Long-term results}

The curative treatment of oesophageal cancer is no longer just surgical. Neoadjuvant treatment with radio-chemotherapy improves the overall survival of stages III whatever the histology, without impacting postoperative morbidity (18). Comparing the oncological results in cirrhotic patients to the normal population therefore also requires an assess ${ }^{-}$ 
ment of the feasibility and tolerance of chemotherapy and radiotherapy.

The series by Fekete et al. included 23 patients, who were immediately resectable on the extension workup and the overall survival at 1 and 3 years was $72 \%$ and $27 \%$ (17). The series by Tachibana et al. included 18 patients, comprising a majority of $\mathrm{pT} 1$ and pT2 tumours, 5 patients received neoadjuvant treatment (radio-chemotherapy) and adjuvant, 8 patients received adjuvant treatment alone (chemotherapy or radiotherapy) (2). Eleven patients were classified Child A and the rest were Child B. The overall survival rate at 1,3 and 5 years was $50 \%, 20.8 \%$ and $20.8 \%$ and lower than in a non-cirrhotic operated population (difference close to significance $\mathrm{P}=0.051$ ). However, excluding the patients who died within 30 postoperative days, the difference in survival at 1 and 3 years was not significant in this group of 15 patients ( $60 \mathrm{vs.} 68 \%$ and $25 \mathrm{vs}$. $43 \%, \mathrm{P}=0.271$ ).

The work of Hii et al. and Lindner et al. show that the oesophageal cancer surgery post-operative complications have no significant impact on the specific survival or the overall survival of patients (19). Therefore, the postoperative morbidity and mortality of the cirrhotic patient does not affect the oncological results of the surgery. It seems lawful to offer curative oncology surgery when the patient's prognosis is linked to cancer and not to underlying liver disease.

The retrospective series by Trivin et al (1) compared 26 patient-cases of oesophageal cancer with cirrhosis treated by radiochemotherapy for oesophageal cancer, with 52 control patients (oesophageal cancer without cirrhosis) treated by radiochemotherapy. The oncological results in terms of survival showed no significant difference in terms of overall survival with a median of 10 months of survival in the case group versus 14 months in the control group and a 2-year survival of $38 \%$ versus $28 \%$. Within the case group, a significant difference in survival at 1 year (67\% vs 0\%) and in tolerance to radiochemotherapy was shown between patients classified as CHILD A $(n=22)$ versus CHILD
B (n = 4); all CHILD B patients developed severe complications from radiochemotherapy, and all died within the first year of which only one death was due to tumour progression. The authors specify that the mortality of the case group was in most cases cirrhosis-specific. Regarding tolerance to chemotherapy, there was no significant difference in terms of side effects except for mucositis and this to the detriment of the control group.

It is lawful to propose a conventional curative therapeutic scheme involving neoadjuvant and adjuvant therapies, depending on the stage and tumour histology, in CHILD $A$ cirrhotic patients, meeting all of the operability criteria (GRADE C).

Cirrhosis and postoperative complications do not worsen the oncological prognosis (GRADE C).

\section{Place of Non-surgical Alternatives}

With regard to locally advanced squamous cell carcinomas of the esophagus treated for curative purposes, this potentially morbid surgery must be balanced with the results of exclusive radiochemotherapy, which allows survival results at 2 years similar to the radiochemotherapy strategy followed by surgery (20).

The other curative treatments (local endoscopic treatments) are to be applied depending on the terrain by previous medical history (20).

\section{Conflict of Interests}

The authors declare no conflict of interests.

\section{Acknowledgements}

We thank the Société Française de Chirurgie Digestive (SFCD) and the Association de Chirurgie Bilio-Pancréatique (ACHBT) for their support.

\section{References}

1. Trivin F, Boucher E, Vauleon E, Cumin I, Le Prise E, Audrain O, et al. Management of esophageal carcinoma associated with cirrhosis: a retrospective case-control analysis. J Oncol. 2009;2009:173421. 
2. Tachibana M, Kotoh T, Kinugasa S, Dhar DK, Shibakita M, Ohno S, et al. Esophageal cancer with cirrhosis of the liver: results of esophagectomy in 18 consecutive patients. Ann Surg Oncol. 2000; 7(10):758-63.

3. Pelucchi C, Gallus S, Garavello W, Bosetti C, La Vecchia C. Alcohol and tobacco use, and cancer risk for upper aerodigestive tract and liver. Eur J Cancer Prev. 2008;17(4):340-4.

4. Randi G, Altieri A, Gallus S, Franceschi S, Negri E, Talamini R, et al. History of cirrhosis and risk of digestive tract neoplasms. Ann Oncol. 2005;16(9):1551-5.

5. Mariette $\mathrm{C}$. Is there a place for esogastric cancer surgery in cirrhotic patients? Ann Surg Oncol. 2008;15(3):680-682.

6. Kral V, Klein J, Havlik R, Aujesky R, Utikal P. Esophagogastric devascularization as the last option in the management of variceal bleeding. Hepatogastroenterology. 2002;49(43):244-6.

7. Voros D, Polydorou A, Polymeneas G, Vassiliou I, Melemeni A, Chondrogiannis $\mathrm{K}$, et al. Long-term results with the modified Sugiura procedure for the management of variceal bleeding: standing the test of time in the treatment of bleeding esophageal varices. World J Surg. 2012;36(3):659-66.

8. Haciyanli M, Genc H, Halici H, Kumkumoglu Y, Gur OS, Ozturk T. Results of modified Sugiura operation in variceal bleeding in cirrhotic and noncirrhotic patients. Hepatogastroenterology. 2003;50(51):784-8.

9. Mariette $C$. Is there a place for esogastric cancer surgery in cirrhotic patients?. Ann Surg Oncol. 2008;15(3):680-682.

10. Bekkar S, Gronnier C, Renaud F, Duhamel A, Pasquer A, Thereaux $J$, et al. Multicentre study of neoadjuvant chemotherapy for stage I and II oesophageal cancer. Br J Surg. 2016;103(7):855-62.

11. Ikeda Y, Kanda T, Kosugi S, Yajima K, Matsuki A, Suzuki T, et al. Gastric cancer surgery for patients with liver cirrhosis. World J Gastrointest Surg. 2009;1(1):49-55.
12. Kato M, Nishida T, Hamasaki T, Kawai N, Yoshio T, Egawa S, et al. Outcomes of ESD for patients with early gastric cancer and comorbid liver cirrhosis: a propensity score analysis. Surgical endoscopy. 2015;29(6):1560-6

13. Lu MS, Liu YH, Wu YC, Kao CL, Liu HP, Hsieh MJ. Is it safe to perform esophagectomy in esophageal cancer patients combined with liver cirrhosis? Interact Cardiovasc Thorac Surg. 2005; $4(5): 423-5$.

14. Dikken JL, van Sandick JW, Allum WH, Johansson J, Jensen LS, Putter $\mathrm{H}$, et al. Differences in outcomes of oesophageal and gastric cancer surgery across Europe. Br J Surg. 2013;100(1):83-94.

15. Brusselaers N, Mattsson F, Lagergren J. Hospital and surgeon volume in relation to long-term survival after oesophagectomy: systematic review and meta-analysis. Gut. 2014;63(9):1393-400.

16. Mariette C, Piessen G, Lamblin A, Mirabel X, Adenis A, Triboulet JP. Impact of preoperative radiochemotherapy on postoperative course and survival in patients with locally advanced squamous cell oesophageal carcinoma. Br J Surg. 2006;93(9):1077-83.

17. Fekete $F$, Belghiti J, Cherqui $D$, Langonnet $F$, Gayet B. Results of esophagogastrectomy for carcinoma in cirrhotic patients. A series of 23 consecutive patients. Ann Surg. 1987;206(1):74-8.

18. Kumagai K, Rouvelas I, Tsai JA, Mariosa D, Klevebro F, Lindblad M, et al. Meta-analysis of postoperative morbidity and perioperative mortality in patients receiving neoadjuvant chemotherapy or chemoradiotherapy for resectable oesophageal and gastrooesophageal junctional cancers. Br J Surg. 2014;101(4):321-38.

19. Hii MW, Smithers BM, Gotley DC, Thomas JM, Thomson I, Martin I, et al. Impact of postoperative morbidity on long-term survival after oesophagectomy. Br J Surg. 2013;100(1):95-104.

20. Mariette C, Piessen G, Briez N, Gronnier C, Triboulet JP. Oesophagogastric junction adenocarcinoma: which therapeutic approach? Lancet Oncol. 2011;12(3):296-305. 